\title{
A self-harm series and its relationship with childhood adversity among adolescents in mainland China: a cross-sectional study
}

\author{
Azhu Han ${ }^{1 \dagger}$, Gengfu Wang ${ }^{2 \dagger}$, Geng Xu' and Puyu Su, ${ }^{1,3^{*}}$ (D)
}

\begin{abstract}
Background: Self-harm (SH) is an emerging problem among Chinese adolescents. The present study aimed to measure the prevalence of SH behaviours and to explore the relationship between childhood adversity and different $\mathrm{SH}$ subtypes among Chinese adolescents.
\end{abstract}

Methods: A total of 5726 middle school students were randomly selected in three cities of Anhui province, China, using a stratified cluster sampling method. SH was categorized into five subtypes (highly lethal self-harm, less lethal self-harm with visible tissue damage, self-harm without visible tissue damage, self-harmful behaviours with latency damage and psychological self-harm). Multivariate logistic regression was used to explore the relationships between childhood adversity and different subtypes of adolescent SH.

Results: The prevalence rates of highly lethal self-harm, less lethal self-harm with visible tissue damage, self-harm without visible tissue damage, self-harmful behaviours with latency damage and psychological self-harm were 6.1, 20.4, 32.0, 20.0 and 23.0\%, respectively. Childhood sexual abuse and physical peer victimization were associated with each SH subtype with adjusted odds ratios (AORs) ranging from 1.23 to 1.76. Highly lethal self-harm was associated with childhood physical peer victimization, sexual abuse, emotional abuse, and emotional neglect. The less lethal SH subtypes (i.e., less lethal self-harm with visible tissue damage, self-harm without visible tissue damage, self-harmful behaviours with latency damage and psychological self-harm) were associated with childhood peer victimization, family life stress event scores and childhood sexual abuse.

Conclusions: A high prevalence of SH exists among Chinese adolescents. The association of childhood adversity with $\mathrm{SH}$ merits serious attention in both future research and preventive interventions.

Keywords: Self-harm, Childhood adversity, Childhood maltreatment, Childhood peer victimization, Childhood family life stress events, Adolescents

\section{Background}

\section{The prevalence of $\mathrm{SH}$}

Self-harm (SH) is characterized by a wide range of behaviours and intentions, including attempted hanging, impulsive self-poisoning, and superficial cutting [1], which aim to relieve a terrible state of mind [2] or

\footnotetext{
* Correspondence: supuyu@ahmu.edu.cn

${ }^{\dagger}$ Equal contributors

${ }^{1}$ Department of Maternal, Child and Adolescent Health, School of Public Health, Anhui Medical University, No.81 Meishan Road, Hefei, Anhui 230032, China

${ }^{3}$ Anhui Provincial Key Laboratory of Population Health and Aristogenics, Hefei, Anhui, China

Full list of author information is available at the end of the article
}

communicate stress [3]. SH behaviour is a significant public health issue worldwide with a high prevalence. Swannell et al. [4] estimated that the lifetime prevalence of non-suicidal self-injury (NSSI) among community adolescents was $17.2 \%$ worldwide and ranged from $1.5 \%$ to $54.8 \%$ across different areas. A meta-analysis of adolescents indicated that the prevalence rates of NSSI in the eastern, central and western regions of mainland China were 21.9, 23.0, and 2.1\%, respectively [5]. Salient differences in the prevalence of SH exist among different areas, even within a country. Two key factors may explain the varied reporting rates of $\mathrm{SH}$ in different studies. The first is that scholars have not reached a 
consensus on the definition of $\mathrm{SH}$, and the second is that different studies have used different methods to measure $\mathrm{SH}$.

Performing an international comparison of the prevalence of SH among adolescents is difficult. Some researchers have argued that the specific method of selfinjury should be considered first rather than the intent behind the self-injurious behaviours when studying these behaviours among adolescents [1]. To the best of our knowledge, the intention underlying $\mathrm{SH}$ is very complex, even for the same form of SH. In contrast, investigations of the specific type of $\mathrm{SH}$ are easier and more precise. Generally, SH is classified into two categories based on whether the participant has suicidal intentions: suicidal SH (e.g., suicide $[6,7]$ ) and non-suicidal SH (e.g., NSSI $[8,9])$. The International Classification of Diseases 10th Revision (ICD-10) defined intentional self-harm as purposely self-inflicted poisoning or injury, including suicide (attempted). The concept of intentional self-harm is mainly focused on apparent self-harmful behaviours. The definition of NSSI in the Diagnostic and Statistical Manual of Mental Disorders, 5th Edition (DSM-5) was intentional self-inflicted injury performed with the expectation of physical harm without suicidal intent [10]. However, both the ICD-10 and DSM-5 classified SH as the result of obvious damage to an individual's own self, whereas implicit forms of self-harmful behaviours were neglected. Based on previous studies [1, 11], five subtypes of $\mathrm{SH}$ were proposed according to the severity of the negative impact of SH: highly lethal self-harm, less lethal self-harm with visible tissue damage, self-harm without visible tissue damage, self-harmful behaviours with latency damage, and psychological self-harm. It is hoped that this classification of $\mathrm{SH}$ will lead to a better understanding of $\mathrm{SH}$ in China.

\section{The relationship between childhood adversity and $\mathrm{SH}$ among adolescents}

Childhood adversity refers to difficult and unpleasant situations and experiences in childhood, including physical, sexual, or emotional abuse, neglect and poverty [12]. Approximately half of adolescents have experienced at least one type of childhood adversity $[8,13]$. Emerging evidence supports a link between childhood adversity and $\mathrm{SH}$. Exposure to childhood abuse increases the risk for later depression [14], NSSI [8] and suicidal behaviours [6, 7], including a significant dose relationship between childhood maltreatment and lifetime suicide attempts [6]. Moreover, a history of childhood sexual abuse increases the likelihood of attempted suicide by almost 4-fold in childhood (4-12 years of age) compared to adulthood (20-29 years of age) [7]. Another study indicates that childhood maltreatment by parents and others increase the risk of NSSI in adolescents, with a cumulative effect with additional perpetrators [8].

Being bullied during childhood not only increases internalizing/externalizing problems and antisocial behaviours [15] but is also associated with $\mathrm{SH}$ in adolescence [9]. In a previous study, frequent bullying reported by three informant groups (children, parents, and teachers) predicted subsequent psychiatric disorders, and the number of childhood peer victimizations reported by teachers served as the strongest predictor [16]. In addition, younger children who were victimized reported significantly more NSSI than older children did [17].

Stressful life events, including family financial difficulties, family conflicts, parental death and divorce [13, 18-21], were more likely to cause $\mathrm{SH}$ among adolescents. Previous studies have reported that negative life event experiences or stressful life event scores and their prevalence are significantly higher in individuals who perform deliberate self-harm (DSH) or attempted suicide [22-24]. Furthermore, a significant dose-response relationship has been found for the number of negative life events and suicidal behaviours [24].

To date, few studies have detailed the association between comprehensive childhood adversity and $\mathrm{SH}$ among Chinese adolescents. Information on the prevalence of each subtype of $\mathrm{SH}$ among Chinese adolescents is also lacking. Therefore, the main aims of the present study were to 1 ) investigate the prevalence of an $\mathrm{SH}$ series in mainland China and 2) further explore possible associations between childhood adversity (i.e., childhood maltreatment, childhood peer victimization, and childhood family life stress events) and the five $\mathrm{SH}$ subtypes.

\section{Methods}

\section{Study design and participants}

This study was part of the research project "Adolescent Health and Risky Behaviours in Anhui Province". A 3-stage, random, cluster sampling approach was employed to select participants in Anhui province in the middle of China. Three cities (Tongling, Chuzhou, and Fuyang) were randomly selected in the first stage. Tongling, Chuzhou, and Fuyang are located in southern, middle and northern Anhui, respectively. In the second stage, one regular middle school and one regular high school were randomly selected from each city. In the third stage, eight target classrooms within each school were randomly selected.

In the selected classes, a total of 6032 students were invited to take part in this study. Of these students, 205 refused to participate in the study and 67 were absent from school at the time of the survey. Thus, the questionnaire was completed by 5760 (95.5\%) students. After screening to determine the completeness of the questionnaires, we obtained an effective sample of 5726 students, including 
2848 males (49.7\%) and 2878 females (50.3\%). The students were aged 12 to 18 years, and the mean age was 14.81 years.

\section{Procedure}

All of the students in the selected classes were invited to participate voluntarily in this study. Students who were absent from class were excluded from the study. Trained interviewers administered anonymous questionnaires in the absence of teachers and to avoid any potential information bias. Each student sat at a separate table. All data were collected in December 2013.

\section{Ethical approval}

The study received approval from the Biomedicine Ethical Committee of Anhui Medical University. All of the participants were fully informed about the purpose of this investigation and were invited to participate voluntarily. Additionally, written informed consent was obtained from the targeted school, each participating student and one of the student's parents.

\section{Measurements Childhood adversity}

In this study, three main types of childhood adversity (i.e., childhood maltreatment, childhood peer victimization, and childhood family life stress events) were investigated.

Childhood maltreatment The questions assessing childhood physical abuse (PA), emotional abuse (EA), sexual abuse (SA), physical neglect (PN), and emotional neglect (EN) were based on the Childhood Trauma Questionnaire Short Form (CTQ-SF) [25]. Questions regarding childhood experiences were rated on a 5-point scale with response options ranging from never to very often $(1=$ never, $2=$ rarely, $3=$ sometimes, $4=$ often, and $5=$ very often). The score for each type of maltreatment ranged from 5 to 25 . The Chinese version of the questionnaire showed acceptable reliability (internal consistency reliability coefficients ranging from 0.78 to 0.90 and test-retest reliability ranging from 0.79 to 0.88 ). The CTQ-SF cut-off scores used in this study were as follows: $\mathrm{PA} \geq 8$; $\mathrm{EA} \geq 9$; $\mathrm{SA} \geq 6$; $\mathrm{PN} \geq 8$; and $\mathrm{EN} \geq 10$ [26].

Childhood peer victimization The measures of childhood peer victimization were based on previous studies $[27,28]$, and two new items were created based on the Chinese social context. The response options were based on a five-point scale as follows: $1=$ never; 2 =rarely; $3=$ sometimes; $4=$ often; and $5=$ very often. First, a standard definition of victimization (qifu) in China was given [29]. Then, the participants were asked how often they had been bullied by peers during their childhood.
Three types of childhood peer victimization were measured. Physical peer victimization was measured by two items: (a1) hitting, kicking, pushing, shoving, or locking indoors (new item); and (a2) blackmailing for money or damaging things. Verbal peer victimization was measured by two items: (b1) calling mean names or making fun or teasing in a hurtful way and (b2) saying mean things about an accent (new item). Relational peer victimization was measured by two items: (c1) excluding others from their group of friends or leaving others out of things on purpose and (c2) telling lies or spreading false rumours about others or sending mean notes and trying to make others unpopular. In this study, we used the criterion that students were bullied at least 2 to 3 times per month to evaluate occurrences of physical, verbal and relational victimization [27].

Childhood family life stress events The following ten items assessing childhood family life stress events were based on previous studies in China [30, 31]: (1) family financial difficulties; (2) parents often fight or quarrel; (3) family trauma (e.g., earthquake, fire, and theft); (4) parents overconsume alcohol or are addicted to gambling; (5) disabled family member; (6) parental absence; (7) family member involved in a crime; (8) parental divorce; (9) death of family member; and (10) family member with a serious illness. The response options for each item were $0=$ no and $1=$ yes. Aggregated scores for each participant were calculated and divided into three groups: 0 score group $(n=2049)$; $1-2$ score group $(n=2337)$; and $3-10$ score group $(n=1340)$.

Self-harm In this study, we considered $\mathrm{SH}$ as a series of self-inflicted and intentional behaviours that caused physical and psychological harm. Based on previous studies [1, 11], we developed 39 items: nine items for highly lethal selfharm; eight items for less lethal self-harm with visible tissue damage; eight items for self-harm without visible tissue damage; nine items for self-harmful behaviours with latency damage; and five items for psychological self-harm. The candidate behaviours for highly lethal self-harm were traditional forms of suicide, which could be similar to suicide attempts in our study. Types of less lethal self-harm with visible tissue damage and self-harm without visible tissue damage were consistent with current reports for non-suicidal SH, including NSSI and DSH; these are actions with a low likelihood of death. Additionally, two new types of SH, including selfharmful behaviours with latency damage and psychological self-harm, were assessed in our study. Although these two types of SH do not result in tissue damage, they may be the primary SH category in adolescents and are usually ignored by researchers.

Participants were asked whether they had self-harmed in the past 6 months. The response option was dichotomized as follows: $0=$ no and $1=$ yes. Highly lethal self-harm was 
measured by nine items: (1) hanging; (2) jumping from a high place; (3) poisoning (e.g., herbicide, pesticide, or carbon monoxide); (4) cutting blood vessels deliberately (e.g., cutting wrist, neck, or fatal parts of the blood vessels); (5) stabbing; (6) electrocution; (7) drowning; (8) overdosing (e.g., hypnagogues); and (9) recreational drug ingestion as $\mathrm{SH}$. Less lethal self-harm with visible tissue damage was measured by eight items: (1) cutting (e.g., arms, legs, or other parts except for fatal parts of the body); (2) burning; (3) self-biting; (4) scratching; (5) gouging; (6) carving words or symbols into skin; (7) sticking needles or pins into skin; and (8) interfering with wound healing. Self-harm without visible tissue damage was measured by eight items: (1) selfhitting; (2) banging head or fist against something; (3) deliberate frostbite; (4) pinching; (5) malaxating; (6) binding; (7) pulling hair; and (8) choking. Self-harmful behaviours with latency damage were measured by nine items: (1) exercising to hurt oneself; (2) denying oneself a necessity as punishment; (3) stopping medication or starving with intent to cause harm; (4) deliberate recklessness (e.g., risk-taking with cars or trains); (5) having intercourse with another (not for the purpose of money or love); (6) overconsuming alcohol (e.g., alcoholism or drinking beyond one's endurance capacity); (7) smoking too much; (8) overeating; and (9) staying up too late (not for working, learning, or entertainment). Psychological self-harm was measured by five items: (1) closing oneself off (forcing oneself to reduce or cease contact with the outside word); (2) distancing oneself from friends on purpose; (3) making oneself unpopular among friends on purpose; (4) insulting oneself; and (5) despising oneself. Each subtype of SH was dichotomized as one or more items versus none.

Covariates We controlled for the potential influence of several sociodemographic variables and depression on $\mathrm{SH}$, including gender (female or male), age (calculated from date of birth and survey date), relationship with mother (good or poor), relationship with father (good or poor), family structure (nuclear family, large family, single-parent family, or other), self-perceived family status (bad, general, or good) and only child (yes or no). Many studies have found that a consistently cited risk factor for $\mathrm{SH}$ is depression [32-34], which is also known to induce $\mathrm{SH}[1,35]$. Zung's Self-Rating Depression Scale (SDS) [36] was adopted in this study to evaluate depression. The SDS consists of 20 items, with a total number of points ranging from 20 to 80 . The questionnaire has been revised in China [37]. A previous study recommended the criterion of an SDS total score greater than or equal to 40 to indicate that participants were at risk for depression [37].

\section{Reliability and validity of the measurements}

The questionnaire was assessed by three experts in this field, and some items were revised based on their suggestions.
Then, the questionnaire was retested (1-week interval) with 156 senior and junior students to guarantee that the content and language were suitable for the study population. The Kappa values ranged from 0.82 to 0.95 . Moreover, the consistency of the test was examined, with a range from 0.72 to 0.84 .

\section{Statistical analysis}

The analyses were performed using SPSS for Windows (version 19.0; SPSS Inc., Chicago, IL, USA). Descriptive statistics were reported for all factors and the prevalence of each SH subtype. Univariate logistic regression analysis was performed to explore the relationships between covariates (e.g., the sociodemographic variables and depression), childhood adversity and each SH subtype. Multivariate logistic regression models were performed to evaluate the relationships between childhood adversity and each SH subtype, with adjustment for sociodemographic variables and depression. All significance tests in this study were evaluated using two-sided tests with a significance level of 0.05 .

\section{Results}

The prevalence of each SH subtype

In this sample, the prevalence rates of highly lethal selfharm, less lethal self-harm with visible tissue damage, selfharm without visible tissue damage, self-harmful behaviours with latency damage and psychological self-harm were $6.1 \%, 20.4 \%, 32.0 \%, 20.0 \%$ and $23.0 \%$, respectively. Each $\mathrm{SH}$ subtype was more common among female students (see Table 1). Additionally, the prevalence of non-involvement in $\mathrm{SH}$ and the frequency of students who were involved overlapped between each $\mathrm{SH}$ subtype, as shown in Additional file 1: Table S1 and Additional file 2: Table S2.

\section{Univariate logistic regression analyses}

As shown in Table 2, the univariate analyses revealed a significant association between (1) childhood maltreatment (OR range from 2.43 to 6.96), (2) childhood peer victimization (OR range from 1.87 to 3.51 ), (3) family life stress events scores (OR range from 1.35 to 3.84) and (4) relationship with both parents (OR range from 0.55 to 0.76) and each SH subtype.

\section{The association between each type of childhood adversity and each SH subtype}

After adjustment for covariates (e.g., sociodemographic variables that were significant in the univariate analysis and depression scale scores), the associations between childhood adversity and $\mathrm{SH}$ in adolescents were weakened. Childhood sexual abuse and physical peer victimization were associated with each $\mathrm{SH}$ subtype, with adjusted odds ratios (AORs) ranging from 1.23 to 1.76 . Highly lethal self-harm was associated with childhood physical peer victimization, emotional abuse, sexual abuse, 
Table 1 Prevalence of self-harm by sample characteristics ( $N=5726$ )

\begin{tabular}{|c|c|c|c|c|c|c|}
\hline \multirow[t]{2}{*}{ Variables } & \multirow[t]{2}{*}{ n (\%) } & \multirow{2}{*}{$\begin{array}{l}\text { Highly lethal } \\
\text { self-harm } \\
\mathrm{n}(\%)\end{array}$} & \multirow{2}{*}{$\begin{array}{l}\text { Less lethal self-harm with } \\
\text { visible tissue damage } \\
\text { n (\%) }\end{array}$} & \multirow{2}{*}{$\begin{array}{l}\text { Self-harm without visible } \\
\text { tissue damage } \\
\text { n (\%) }\end{array}$} & \multirow{2}{*}{$\begin{array}{l}\text { Self-harmful behaviors } \\
\text { with latency damage } \\
\text { n (\%) }\end{array}$} & \multirow{2}{*}{$\begin{array}{l}\text { Psychological } \\
\text { self-harm } \\
\text { n (\%) }\end{array}$} \\
\hline & & & & & & \\
\hline \multicolumn{7}{|l|}{ Gender } \\
\hline Female & $2878(50.3)$ & $197(6.8)$ & $763(26.5)$ & $972(33.8)$ & $600(20.8)$ & $749(26.0)$ \\
\hline Male & $2848(49.7)$ & $152(5.3)$ & $405(14.2)$ & $862(30.3)$ & $545(19.1)$ & $567(19.9)$ \\
\hline \multicolumn{7}{|l|}{ Age } \\
\hline 12 years & $876(15.3)$ & $28(3.2)$ & $133(15.2)$ & $217(24.8)$ & $91(10.4)$ & 119 (13.6) \\
\hline 13 years & $919(16.0)$ & $59(6.4)$ & $191(20.8)$ & $297(32.3)$ & $170(18.5)$ & $200(21.8)$ \\
\hline 14 years & $842(14.7)$ & $56(6.7)$ & $180(21.4)$ & $239(28.4)$ & $156(18.5)$ & 165 (19.6) \\
\hline 15 years & $803(14.0)$ & $56(7.0)$ & $174(21.7)$ & $234(29.1)$ & $170(21.2)$ & $185(23.0)$ \\
\hline 16 years & $892(15.6)$ & $63(7.1)$ & $178(20.0)$ & $302(33.9)$ & $187(21.0)$ & $234(26.2)$ \\
\hline 17 years & $996(17.4)$ & $62(6.2)$ & $226(22.7)$ & $382(38.4)$ & $267(26.8)$ & $295(29.6)$ \\
\hline 18 years & $398(7.0)$ & $25(6.3)$ & $86(21.6)$ & $163(41.0)$ & $104(26.1)$ & $118(29.6)$ \\
\hline \multicolumn{7}{|c|}{ Self-perceived family status } \\
\hline Bad & $800(14.0)$ & $57(7.1)$ & $183(22.9)$ & $304(38.0)$ & $187(23.4)$ & $227(28.4)$ \\
\hline General & $4377(76.4)$ & $256(5.8)$ & $877(20.0)$ & $1370(31.3)$ & $846(19.3)$ & $967(22.1)$ \\
\hline Good & $549(9.6)$ & $36(6.6)$ & $108(19.7)$ & $160(29.1)$ & $112(20.4)$ & $122(22.2)$ \\
\hline \multicolumn{7}{|l|}{ Relationship with mother } \\
\hline Good & $4373(76.4)$ & $227(5.2)$ & $843(19.3)$ & $1358(31.1)$ & $795(18.2)$ & $927(21.2)$ \\
\hline Poor & $1353(23.6)$ & $122(9.0)$ & $325(24.0)$ & $476(35.2)$ & $350(25.9)$ & $389(28.8)$ \\
\hline \multicolumn{7}{|l|}{ Relationship with father } \\
\hline Good & 3815 (66.6) & $191(5.0)$ & $700(18.3)$ & $1135(29.8)$ & $666(17.5)$ & $779(20.4)$ \\
\hline Poor & $1911(33.4)$ & $158(8.3)$ & $468(24.5)$ & $699(36.6)$ & $479(25.1)$ & $537(28.1)$ \\
\hline \multicolumn{7}{|l|}{ Only child } \\
\hline Yes & $2469(43.1)$ & $113(4.6)$ & $399(16.2)$ & $711(28.8)$ & $435(17.6)$ & $481(19.5)$ \\
\hline No & $3257(56.9)$ & $236(7.2)$ & $769(23.6)$ & $1123(34.5)$ & $710(21.8)$ & $835(25.6)$ \\
\hline \multicolumn{7}{|l|}{ Family structure } \\
\hline Nuclear family & $3792(66.2)$ & $225(5.9)$ & $765(20.2)$ & $1190(31.4)$ & $761(20.1)$ & $867(22.9)$ \\
\hline Lager family & $1353(23.6)$ & $91(6.7)$ & $276(20.4)$ & $447(33.0)$ & $256(18.9)$ & $310(22.9)$ \\
\hline Single-parent family & $469(8.2)$ & $26(5.5)$ & $99(21.1)$ & $152(32.4)$ & $99(21.1)$ & $112(23.9)$ \\
\hline Other & $112(2.0)$ & $7(6.3)$ & $28(25.0)$ & $45(40.2)$ & $29(25.9)$ & $27(24.1)$ \\
\hline \multicolumn{7}{|c|}{ Childhood physical peer victimization } \\
\hline Yes & $4494(78.5)$ & $213(4.7)$ & $778(17.3)$ & $1264(28.1)$ & $761(16.9)$ & 879 (19.6) \\
\hline No & $1232(21.5)$ & $136(11.0)$ & $390(31.7)$ & $570(46.3)$ & $384(31.2)$ & $437(35.5)$ \\
\hline \multicolumn{7}{|c|}{ Childhood verbal peer victimization } \\
\hline Yes & $3325(58.1)$ & $152(4.6)$ & $525(15.8)$ & $832(25.0)$ & $522(15.7)$ & $552(16.6)$ \\
\hline No & $2401(41.9)$ & $197(8.2)$ & $643(26.8)$ & $1002(41.7)$ & $623(25.9)$ & $764(31.8)$ \\
\hline \multicolumn{7}{|c|}{ Childhood relational peer victimization } \\
\hline Yes & $4143(72.4)$ & $175(4.2)$ & $615(14.8)$ & $1039(25.1)$ & $578(14.0)$ & $674(16.3)$ \\
\hline No & $1583(27.6)$ & $174(11.0)$ & $553(34.9)$ & $795(50.2)$ & $567(35.8)$ & $642(40.6)$ \\
\hline \multicolumn{7}{|l|}{ Physical abuse } \\
\hline Yes & $425(7.4)$ & $71(16.7)$ & $155(36.5)$ & $236(55.5)$ & $171(40.2)$ & $205(48.2)$ \\
\hline No & 5301 (92.6) & $278(5.2)$ & $1013(19.1)$ & 1598 (30.1) & $974(18.4)$ & $1111(21.0)$ \\
\hline
\end{tabular}

Emotional abuse 
Table 1 Prevalence of self-harm by sample characteristics ( $N=5726)$ (Continued)

\begin{tabular}{|c|c|c|c|c|c|c|}
\hline \multirow[t]{2}{*}{ Variables } & \multirow[t]{2}{*}{ n (\%) } & \multirow[t]{2}{*}{$\begin{array}{l}\text { Highly lethal } \\
\text { self-harm } \\
\mathrm{n}(\%)\end{array}$} & \multirow[t]{2}{*}{$\begin{array}{l}\text { Less lethal self-harm with } \\
\text { visible tissue damage } \\
\text { n (\%) }\end{array}$} & \multirow[t]{2}{*}{$\begin{array}{l}\text { Self-harm without visible } \\
\text { tissue damage } \\
\text { n (\%) }\end{array}$} & \multirow[t]{2}{*}{$\begin{array}{l}\text { Self-harmful behaviors } \\
\text { with latency damage } \\
\text { n (\%) }\end{array}$} & \multirow[t]{2}{*}{$\begin{array}{l}\text { Psychological } \\
\text { self-harm } \\
n(\%)\end{array}$} \\
\hline & & & & & & \\
\hline Yes & $632(11.0)$ & $112(17.7)$ & $263(41.6)$ & $356(56.3)$ & $257(40.7)$ & $308(48.7)$ \\
\hline No & $5094(89.0)$ & $237(4.7)$ & $905(17.8)$ & $1478(29.0)$ & $888(17.4)$ & $1008(19.8)$ \\
\hline \multicolumn{7}{|c|}{ Sexual abuse } \\
\hline Yes & $499(8.7)$ & $88(17.6)$ & $206(41.3)$ & $268(53.7)$ & $210(42.1)$ & $220(44.1)$ \\
\hline No & $5227(91.3)$ & $261(5.0)$ & $962(18.4)$ & $1566(30.0)$ & $935(17.9)$ & $1096(21.0)$ \\
\hline \multicolumn{7}{|c|}{ Physical neglect } \\
\hline Yes & $379(6.6)$ & $77(20.3)$ & $166(43.8)$ & $229(60.4)$ & $179(47.2)$ & $198(52.2)$ \\
\hline No & $5347(93.4)$ & $272(5.1)$ & $1002(18.7)$ & $1605(30.0)$ & $966(18.1)$ & $1118(20.9)$ \\
\hline \multicolumn{7}{|c|}{ Emotional neglect } \\
\hline Yes & $228(4.0)$ & $63(27.6)$ & $111(48.7)$ & $144(63.2)$ & $116(50.9)$ & $124(54.4)$ \\
\hline No & $5498(96.0)$ & $286(5.2)$ & $1057(19.2)$ & $1690(30.7)$ & $1029(18.7)$ & $1192(21.7)$ \\
\hline \multicolumn{7}{|c|}{ Family life stress event scores } \\
\hline 0 & 2049 (35.8) & $95(4.6)$ & $239(11.7)$ & $417(20.4)$ & $258(12.6)$ & $255(12.4)$ \\
\hline $1-2$ & $2337(40.8)$ & $144(6.2)$ & $514(22.0)$ & 805 (34.4) & $484(20.7)$ & $588(25.2)$ \\
\hline $3-10$ & $1340(23.4)$ & $110(8.2)$ & 415 (31.0) & $612(45.7)$ & $403(30.1)$ & $473(35.3)$ \\
\hline \multicolumn{7}{|c|}{ Depression } \\
\hline Yes & 3711 (64.8) & $301(8.1)$ & $891(24.0)$ & $1341(36.1)$ & $896(24.1)$ & $1023(27.6)$ \\
\hline No & 2015 (35.2) & $48(2.4)$ & 277 (13.7) & $493(24.5)$ & $249(12.4)$ & $293(14.5)$ \\
\hline
\end{tabular}

and emotional neglect. Childhood peer victimization, family life stress event scores and childhood sexual abuse were associated with less lethal subtypes of SH. Additionally, the associations between childhood adversity and the four less lethal SH subtypes were similar in this study (see Table 3). We also performed a multivariate logistic regression analysis to confirm the relationships between childhood adversity and each SH subtype, with adjustments for all sociodemographic variables and depression. The results showed similar relationships (see Additional file 3: Table S3).

\section{Discussion}

\section{Prevalence of each type of SH}

In this study, $\mathrm{SH}$ was considered as a series of selfinflicted and intentional behaviours that caused physical and psychological harm. The prevalence rates of highly lethal self-harm, less lethal self-harm with visible tissue damage, self-harm without visible tissue damage, selfharmful behaviours with latency damage and psychological self-harm were 6.1, 20.4, 32.0, 20.0 and 23.0\%, respectively. The prevalence of highly lethal self-harm was $6.1 \%$ lower than the prevalence of the other four subtypes of $\mathrm{SH}$, which was consistent with previous reports of the prevalence of suicidal attempts ranging from 4.0 to $7.0 \%$ in the general adolescent population [33, 38-40]. Moreover, non-suicidal SH (i.e., less lethal self-harm with visible tissue damage and self-harm without visible tissue damage) was consistent with the results of recent studies in China [8, 41] and was higher than the pooled NSSI prevalence of adolescents worldwide [4]. Additionally, our study examined the prevalence rates of self-harmful behaviours with latency damage and psychological self-harm, which accounted for approximately one-fifth each. However, due to the lack of a similar analysis, we could not compare our results with the results of other studies. Although these two $\mathrm{SH}$ subtypes may exert less harm on adolescents, future research is required to provide an understanding of the negative impact on adolescent health.

\section{Childhood maltreatment and SH}

All types of childhood maltreatment were linked to $\mathrm{SH}$ in adolescents in the univariate analysis. After rigorously adjusting a series of covariates, childhood sexual abuse was still significantly associated with each $\mathrm{SH}$ subtype. This finding is consistent with previous studies suggesting that a history of childhood sexual abuse significantly increased the risk of onset and persistence of suicide attempts in adolescents $[7,13]$. Additionally, these findings serve as a reminder that childhood sexual abuse may have a more robust relationship with $\mathrm{SH}$ than the other risk factors mentioned in our study. Based on this finding, we can deduce that strategies towards the prevention of $\mathrm{SH}$ in adolescents need to pay more attention to individuals who have experienced maltreatment during childhood, especially childhood sexual abuse. Additionally, Weierch [42] supported a theoretical 
Table 2 Unadjusted OR (95\% Cl) for self-harm by univariate analysis

\begin{tabular}{|c|c|c|c|c|c|c|}
\hline & & $\begin{array}{l}\text { Highly lethal } \\
\text { self-harm }\end{array}$ & $\begin{array}{l}\text { Less lethal self-harm with } \\
\text { visible tissue damage }\end{array}$ & $\begin{array}{l}\text { Self-harm without } \\
\text { visible tissue damage }\end{array}$ & $\begin{array}{l}\text { Self-harmful behaviors } \\
\text { with latency damage }\end{array}$ & $\begin{array}{l}\text { Psychological } \\
\text { self-harm }\end{array}$ \\
\hline Gender & Female: Male & $1.30(1.05,1.62)^{*}$ & $2.18(1.90,2.49)^{* * *}$ & $1.18(1.05,1.31)^{* *}$ & $1.11(0.98,1.27)$ & $1.42(1.25,1.60)^{* * *}$ \\
\hline Age & & $1.07(1.02,1.34)^{*}$ & $1.06(1.02,1.09)^{* * *}$ & $1.11(1.08,1.14)^{* * *}$ & $1.17(1.13,1.21)^{* * *}$ & $1.16(1.12,1.20)^{* * *}$ \\
\hline \multirow{3}{*}{$\begin{array}{l}\text { Self-perceived } \\
\text { family status }\end{array}$} & Ref: Bad & & & & & \\
\hline & General & $0.81(0.60,1.09)$ & $0.85(0.71,1.01)$ & $0.74(0.64,0.87)^{* * *}$ & $0.79(0.66,0.94)^{* *}$ & $0.72(0.60,0.85)^{* * *}$ \\
\hline & Good & $0.92(0.59,1.41)$ & $0.83(0.63,1.08)$ & $0.67(0.53,0.85)^{* * *}$ & $0.84(0.65,1.09)$ & $0.72(0.56,0.93)^{*}$ \\
\hline $\begin{array}{l}\text { Relationship with } \\
\text { mother }\end{array}$ & Good: Poor & $0.55(0.44,0.70)^{* * *}$ & $0.76(0.65,0.87)^{* * *}$ & $0.83(0.73,0.94)^{* *}$ & $0.64(0.55,0.74)^{* * *}$ & $0.67(0.58,0.77)^{* * *}$ \\
\hline $\begin{array}{l}\text { Relationship with } \\
\text { father }\end{array}$ & Good: Poor & $0.59(0.47,0.73)^{* * *}$ & $0.69(0.61,0.79)^{* * *}$ & $0.73(0.65,0.83)^{* * *}$ & $0.63(0.55,0.72)^{* * *}$ & $0.66(0.58,0.75)^{* * *}$ \\
\hline Only child & Yes: No & $0.61(0.49,0.77)^{* * *}$ & $0.62(0.55,0.71)^{* * *}$ & $0.77(0.69,0.86)^{* * *}$ & $0.77(0.67,0.87)^{* * *}$ & $0.70(0.62,0.80)^{* * *}$ \\
\hline \multirow[t]{4}{*}{ Family structure } & \multicolumn{6}{|c|}{ Ref: Nuclear Family } \\
\hline & Lager family & $1.14(0.89,1.47)$ & $1.01(0.87,1.18)$ & $1.08(0.95,1.23)$ & $0.93(0.79,1.09)$ & $1.01(0.87,1.16)$ \\
\hline & $\begin{array}{l}\text { Single-parent } \\
\text { Family }\end{array}$ & $0.93(0.61,1.41)$ & $1.06(0.84,1.34)$ & $1.05(0.85,1.29)$ & $1.07(0.84,1.35)$ & $1.06(0.85,1.33)$ \\
\hline & Other & $1.06(0.49,2.30)$ & $1.32(0.85,2.04)$ & $1.47(0.99,2.16)$ & $1.40(0.91,2.14)$ & $1.07(0.70,1.66)$ \\
\hline $\begin{array}{l}\text { Childhood physical } \\
\text { peer victimization }\end{array}$ & Yes: No & $2.49(1.99,3.12)^{* * *}$ & $2.21(1.92,2.55)^{* * *}$ & $2.20(1.93,2.50)^{* * *}$ & $2.22(1.92,2.56)^{* * *}$ & $2.26(1.97,2.60)^{* * *}$ \\
\hline $\begin{array}{l}\text { Childhood verbal } \\
\text { peer victimization }\end{array}$ & Yes: No & $1.87(1.50,2.32)^{* * *}$ & $1.95(1.71,2.22)^{* * *}$ & $2.15(1.92,2.40)^{* * *}$ & $1.88(1.65,2.14)^{* * *}$ & $2.35(2.07,2.66)^{* * *}$ \\
\hline $\begin{array}{l}\text { Childhood relational } \\
\text { peer victimization }\end{array}$ & Yes: No & $2.80(2.25,3.48)^{* * *}$ & $3.08(2.69,3.52)^{* * *}$ & $3.01(2.67,3.40)^{* * *}$ & $3.44(3.01,3.94)^{* * *}$ & $3,51(3.08,4.00)^{* * *}$ \\
\hline Physical abuse & Yes: No & $3.62(2.73,4.81)^{* * *}$ & $2.43(1.97,3.00)^{* * *}$ & $2.89(2.37,3.54)^{* * *}$ & $2.99(2.43,3.68)^{* * *}$ & $3.51(2.87,4.30)^{* * *}$ \\
\hline Emotional abuse & Yes: No & $4.41(3.46,5.62)^{* * *}$ & $3.30(2.77,3.93)^{* * *}$ & $3.16(2.67,3.74)^{* * *}$ & $3.25(2.73,3.87)^{* * *}$ & $3.85(3.25,4.57)^{* * *}$ \\
\hline Sexual abuse & Yes: No & $4.07(3.14,5.29)^{* * *}$ & $3.12(2.57,3.78)^{* * *}$ & $2.71(2.25,3.27)^{* * *}$ & $3.34(2.76,4.04)^{* * *}$ & $2.97(2.46,3.59)^{* * *}$ \\
\hline Physical neglect & Yes: No & $4.76(3.60,6.28)^{* * *}$ & $3.38(2.73,4.19)^{* * *}$ & $3.56(2.87,4.41)^{* * * *}$ & $4.06(3.28,5.02)^{* * *}$ & $4.14(3.35,5.12)^{* * *}$ \\
\hline Emotional neglect & Yes: No & $6.96(5.08,9.52)^{* * *}$ & $3.99(3.05,5.21)^{* * *}$ & $3.86(2.93,5.09)^{* * *}$ & $4.50(3.44,5.88)^{* * *}$ & $4.31(3.29,5.63)^{* * *}$ \\
\hline \multirow{3}{*}{$\begin{array}{l}\text { Family life stress } \\
\text { event scores }\end{array}$} & Ref: 0 & & & & & \\
\hline & $1-2$ & $1.35(1.04,1.76)^{*}$ & $2.14(1.81,2.52)^{* * *}$ & $2.06(1.79,2.36)^{* * *}$ & $1.81(1.54,2.14)^{* * *}$ & $2.37(2.01,2.78)^{* * *}$ \\
\hline & $3-10$ & $1.84(1.39,2.44)^{* * * *}$ & $3.40(2.84,4.06)^{* * *}$ & $3.29(2.83,3.83)^{* * *}$ & $2.99(2.51,3.56)^{* * *}$ & $3.84(3.23,4.56)^{* * *}$ \\
\hline Depression & Yes: No & $3.62(2.65,4.93)^{* * *}$ & $1.98(1.71,2.30)^{* * *}$ & $1.75(1.55,1.97)^{* * *}$ & $2.26(1.94,2.63)^{* * *}$ & $2.24(1.94,2.58)^{* * *}$ \\
\hline
\end{tabular}

Note: $95 \% \mathrm{Cl}=95 \%$ confidence interval. ${ }^{*} P<0.05$; ${ }^{* *} P<0.01 ;{ }^{* * *} P<0.001$

model in which posttraumatic stress disorder (PTSD) independently mediated the relationship between childhood sexual abuse and the frequency of NSSI. In this study, we controlled for depression as a covariate. Therefore, future research should focus on other mediators of those relationships to obtain a better understanding of the results in our study and provide suggestions for the prevention of $\mathrm{SH}$.

\section{Childhood peer victimization and $\mathrm{SH}$}

Childhood peer victimization was associated with $\mathrm{SH}$, particularly childhood physical peer victimization, which was consistent with the findings of a meta-analysis that showed positive links between peer victimization and NSSI [17]. Previous studies indicated that younger children who suffered from victimization had more reported
NSSI behaviours as children and adolescents [17]. Adolescents who were bullied between seven and 10 years of age had an increased risk for $\mathrm{SH}$ in late adolescence, which indirectly led to depression in early adolescence. Moreover, the association between being bullied and $\mathrm{SH}$ in adolescents was partially mediated by depression symptoms [9]. However, after adjusting for the depression scale scores in our study, an association still existed between each SH subtype and childhood physical peer victimization. Garisch's [43] study demonstrated that alexithymia moderated and partially mediated the association between a history of bullying and DSH. In the future, studies are needed to explore the mechanisms underlying the relationship between childhood peer victimization and $\mathrm{SH}$, including mediators and moderators. 
Table 3 Multivariable logistic regression analysis showing the AOR (95\% Cl) between childhood adversity and five subtypes of self-harm $(N=5726)$

\begin{tabular}{|c|c|c|c|c|c|c|}
\hline & & $\begin{array}{l}\text { Highly lethal } \\
\text { self-harm }\end{array}$ & $\begin{array}{l}\text { Less lethal self-harm with } \\
\text { visible tissue damage }\end{array}$ & $\begin{array}{l}\text { Self-harm without visible } \\
\text { tissue damage }\end{array}$ & $\begin{array}{l}\text { Self-harmful behaviors with } \\
\text { latency damage }{ }^{d}\end{array}$ & $\begin{array}{l}\text { Psychological } \\
\text { self-harme }^{\text {e }}\end{array}$ \\
\hline $\begin{array}{l}\text { Childhood physical } \\
\text { peer victimization }\end{array}$ & Yes: No & $1.48(1.11,1.97)^{* *}$ & $1.52(1.28,1.82)^{* * *}$ & $1.27(1.08,1.48)^{* *}$ & $1.27(1.06,1.51)^{* *}$ & $1.23(1.03,1.46)^{*}$ \\
\hline $\begin{array}{l}\text { Childhood verbal } \\
\text { peer victimization }\end{array}$ & Yes: No & $1.11(0.85,1.44)$ & $1.25(1.07,1.45)^{* *}$ & $1.42(1.24,1.61)^{* * *}$ & $1.15(0.99,1.34)$ & $1.52(1.31,1.76)^{* * *}$ \\
\hline $\begin{array}{l}\text { Childhood relational } \\
\text { peer victimization }\end{array}$ & Yes: No & $1.17(0.86,1.58)$ & $1.69(1.42,2.00)^{* * *}$ & $1.87(1.61,2.18)^{* * *}$ & $2.24(1.89,2.65)^{* * *}$ & $1.90(1.61,2.25)^{* * *}$ \\
\hline Physical abuse & Yes: No & $0.98(0.66,1.45)$ & $0.96(0.73,1.26)$ & $1.24(0.97,1.59)$ & $1.09(0.83,1.42)$ & $1.45(1.12,1.88)^{* *}$ \\
\hline Emotional abuse & Yes: No & $1.58(1.09,2.30)^{*}$ & $1.14(0.90,1.46)$ & $1.06(0.84,1.33)$ & $0.90(0.70,1.15)$ & $1.15(0.90,1.46)$ \\
\hline Sexual abuse & Yes: No & $1.76(1.27,2.45)^{* * *}$ & $1.67(1.33,2.10)^{* * *}$ & $1.33(1.07,1.65)^{*}$ & $1.61(1.28,2.03)^{* * *}$ & $1.30(1.03,1.63)^{*}$ \\
\hline Physical neglect & Yes: No & $1.43(0.97,2.11)$ & $1.30(0.98,1.71)$ & $1.32(1.01,1.72)^{*}$ & $1.40(1.07,1.85)^{*}$ & $1.39(1.06,1.83)^{*}$ \\
\hline Emotional neglect & Yes: No & $1.79(1.16,2.76)^{* *}$ & $1.17(0.82,1.65)$ & $1.07(0.76,1.51)$ & $1.15(0.81,1.62)$ & $0.92(0.65,1.30)$ \\
\hline \multirow{3}{*}{$\begin{array}{l}\text { Family life stress } \\
\text { event scores }\end{array}$} & Ref: 0 & & & & & \\
\hline & $1-2$ & $0.99(0.75,1.32)$ & $1.63(1.37,1.95)^{* * *}$ & $1.67(1.44,1.93)^{* * *}$ & $1.45(1.22,1.73)^{* * *}$ & $1.85(1.55,2.20)^{* * *}$ \\
\hline & $3-10$ & $0.84(0.60,1.16)$ & $1.97(1.61,2.41)^{* * *}$ & $2.02(1.70,2.41)^{* * *}$ & $1.72(1.40,2.10)^{* * *}$ & $2.13(1.75,2.59)^{* * *}$ \\
\hline
\end{tabular}

Note: adjusted for gender, age, relationship with mother, relationship with father, only child and depression scale scores; ${ }^{b}$ adjusted for gender, age, relationship with mother, relationship with father, only child and depression scale scores; 'adjusted for gender, age, self-perceived family status, relationship with mother, relationship with father, only child and depression scale scores; ${ }^{d}$ adjusted for age, self-perceived family status, relationship with mother, relationship with father, only child and depression scale scores; eadjusted for gender, age, self-perceived family status, relationship with mother, relationship with father, only child and depression scale scores

* $P<0.05 ; * P<0.01 ; * * P<0.001$

\section{Childhood family life stressful events and SH}

An increasing amount of evidence has shown that family life stress elevates the risk for $\mathrm{SH}$. Some research has suggested that stressful life events, such as a single-parent family, parental death or divorce, are important risk factors for $\mathrm{SH}$ in adolescents [13, 44]. Studies have also reported that adolescents from families with conflicts, non-intact families, and families with financial hardships were more likely to engage in suicide $[18,19,45]$. Our results indicated that family life stress events were significantly associated with $\mathrm{SH}$ but not with highly lethal self-harm in Chinese adolescents. Contradictory findings have reported that the number of negative life events in the previous year increased not only the risk of NSSI [46] but also suicide attempts [47]. Indeed, negative life events experiences may influence the stress system by altering stress systems, such as influencing individuals' hormones and neurotransmitters, and the subsequent imbalance may lead to suicidal behaviour [48].

\section{The pattern of the association between childhood adversity and each SH subtype}

The association between childhood adversity with highly lethal self-harm identified in our study was different from the associations with the non-lethal SH subtypes. Our study indicated that childhood emotional abuse and neglect were associated with highly lethal self-harm but had no association with the other four SH subtypes. Previous studies found that childhood emotional abuse and neglect were associated with suicidal ideation and attempts in adolescents, particularly for serious suicide attempts [49]. Furthermore, childhood emotional abuse had indirect harmful effects on suicidal behaviours in adolescents [14]. Conversely, regarding the childhood peer victimization and childhood family life stress event scores, highly lethal self-harm was only associated with childhood physical peer victimization, whereas the other four $\mathrm{SH}$ subtypes were associated with the three types of childhood victimization and childhood family life stress event scores after the adjustment of covariates. These findings revealed that highly lethal self-harm differs from the other four SH subtypes in its nature. That is likely a consequence of individual genetics over the lifetime, exposure to environmental factors, and the interaction of those two factors. A growing body of studies has reported that suicidal behaviours are associated with a number of genes, including 5-HTTLPR polymorphisms [50], serotonin receptors and transporters, and brainderived neurotrophic factors (BDNFs) [51], but these findings are controversial. Interactions between genetics and the environment may play significant roles in the risk for suicidal behaviours. Only those environmental factors that are serious or persistent, such as childhood physical peer victimization and sexual abuse, may be regarded as environmental harbouring stressors that affect suicidal behaviours. However, these findings are best regarded as preliminary data that need to be validated in future studies. 


\section{Limitations}

The prevalence of a series of self-inflicted and intentional behaviours was explored in this cross-sectional study. We acquired a large and diverse sample. However, the limitations of this study must also be noted to better understand these results. First, this study was a cross-sectional study; therefore, a causal conclusion cannot be drawn. Future studies should use a prospective design to validate these specific relationships. Second, recall bias might affect the accuracy of the results due to the childhood adversity that was experienced in primary school or during an earlier period. Third, the participants in this study were mainly recruited from schools. The few students who dropped out or skipped school missed the investigation. However, because these students might have more health problems and higher risks of $\mathrm{SH}$, future studies should include adolescents from multiple sources. Finally, correlations were found among multiple types of childhood adversity and $\mathrm{SH}$. In this study, we examined only the association between each type of childhood adversity and each type of $\mathrm{SH}$. We did not examine the interaction between several forms of childhood adversity and $\mathrm{SH}$. Future studies could use a more effective method to explore these correlations.

\section{Conclusions}

This study investigated the prevalence of each type of $\mathrm{SH}$ among Chinese adolescents by utilizing a large-scale survey sample. The study also examined the association between childhood adversity and SH. We found a high prevalence of $\mathrm{SH}$ among Chinese adolescents, which indicated a significant relationship between childhood adversity and $\mathrm{SH}$. Therefore, strategies to prevent $\mathrm{SH}$ among adolescents may be more beneficial if they address childhood adversity experiences. Further investigations are needed to explore the mechanisms underlying the association between childhood adversity and different $\mathrm{SH}$ subtypes.

\section{Additional files}

Additional file 1: Table S1. Frequency of overlap between different types of self-harm. (DOC $31 \mathrm{~kb}$ )

Additional file 2: Table S2. Prevalence of involved in different numbers of self-harm by sample characteristics $(N=5726)$. (DOC 106 kb)

Additional file 3: Table S3. Multivariable logistic regression analysis showing the AOR $(95 \% \mathrm{Cl})$ between childhood adversity and five subtypes of self-harm $(N=5726)$. Results of multivariate logistic regression analysis to confirm the relationships between childhood adversity and each SH subtype, with adjustments for all sociodemographic variables and depression. (DOC $57 \mathrm{~kb}$ )

\section{Abbreviations}

AORs: Adjusted odds ratios; BDNFs: Brain-derived Neurotrophic Factors; Cl: Confidence intervals; CTQ-SF: Childhood Trauma Questionnaire Short Form; DSH: Deliberate self-harm; DSM-5: Diagnostic and Statistical Manual of Mental Disorders, 5th Edition; EA: Emotional abuse; EN: Emotional neglect; ICD-10: International Classification of Diseases 10th Revision; NSSI: Non-suicidal self-injury; PA: Physical abuse; PN: Physical neglect; PTSD: Posttraumatic stress disorder; SA: Sexual abuse; SDS: Self-Rating Depression Scale; SH: Self-harm

Acknowledgements

The authors are extremely grateful to all of the participants.

Funding

This work was supported by grants from the National Natural Science Foundation of China (81102145 and 81573163).

Availability of data and materials

All data and materials related to the study can be obtained by contacting the corresponding author.

\section{Authors' contributions}

PS and AH developed the concept and design for the manuscript; PS, GW, and GX acquired and prepared data for analysis; GW and AH drafted the manuscript; GW and PS guided the authorship of the critical revision of the manuscript for important intellectual content; and PS obtained funding and supervised the study. All authors read and approved the final version of the manuscript.

\section{Ethics approval and consent to participate}

The study was approved by the Biomedicine Ethical Committee of Anhui Medical University. The participants were fully informed of the purpose of the study and were invited to participate voluntarily. Written informed consent was obtained from the school, each participating student and either of the student's parents.

Consent for publication

Not applicable.

\section{Competing interests}

The authors declare that they have no competing interests.

\section{Publisher's Note}

Springer Nature remains neutral with regard to jurisdictional claims in published maps and institutional affiliations.

\section{Author details}

${ }^{1}$ Department of Maternal, Child and Adolescent Health, School of Public Health, Anhui Medical University, No.81 Meishan Road, Hefei, Anhui 230032, China. ${ }^{2}$ Department of Maternal, Child and Adolescent Health, School of Public Health, Tianjin Medical University, No. 22 Qixiangtai Road, Tianjin 300070, China. ${ }^{3}$ Anhui Provincial Key Laboratory of Population Health and Aristogenics, Hefei, Anhui, China.

Received: 2 May 2017 Accepted: 16 January 2018

Published online: 01 February 2018

\section{References}

1. Skegg K. Self-harm. Lancet. 2005;366(9495):1471-83.

2. Rasmussen S, Hawton K, Philpott-Morgan S, O'Connor RC. Why do adolescents self-harm? Crisis. 2016;37(3):176-83.

3. Edmondson AJ, Brennan CA, House AO. Non-suicidal reasons for self-harm: a systematic review of self-reported accounts. J Affect Disord. 2016;191:109-17.

4. Swannell SV, Martin GE, Page A, Hasking P, St-John NJ. Prevalence of nonsuicidal self-injury in nonclinical samples: systematic review, meta-analysis and meta-regression. Suicide Life Threat Behav. 2014;44(3):273-303.

5. Pan Z, Mao SJ, Tang HM, Fu YY, Sun WX, Liao ZW, Li JN, Qiu HH, Zhu JY, Huang P. Meta-analysis on non suicidal self-injury among college students in China. ChinJ Sch Health. 2016;37(6):878-81.

6. Bruwer B, Govender R, Bishop M, Williams DR, Stein DJ, Seedat S. Association between childhood adversities and long-term suicidality among south Africans from the results of the south African stress and health study: a cross-sectional study. BMJ Open. 2014;4(6):e004644.

7. Bruffaerts R, Demyttenaere K, Borges G, Haro JM, Chiu WT, Hwang I, Karam EG, Kessler RC, Sampson N, Alonso J. Childhood adversities as risk factors for on set and persistence of suicidal behaviour. Br J Psychiatry. 2010;197(1):20-7.

8. Wan YH, Chen J, Sun Y, Tao F. Impact of childhood abuse on the risk of non-suicidal self-injury in mainland Chinese adolescents. PLoS One. 2015; 10(6):e0131239. 
9. Lereya ST, Winsper C, Heron J, Lewis G, Gunnell D, Fisher HL, Wolke D. Being bullied during childhood and the prospective pathways to self-harm in late adolescence. J Am Acad Child Adolesc Psychiatry. 2013;52(6):608-18.

10. Shaffer D, Jacobson C. Proposal to the DSM-V childhood disorder and mood disorder work groups to include non-suicidal self-injury (NSSI) as a DSM-V disorder. Am Psychiatr Assoc. 2009;1-21.

11. Su PY, Hao JH, Huang ZH, Tao FB. An investigation on self-harm episodes and their relationship with suicidal psychology and behaviors in 2713 college students. Chin J Epidemiol. 2010;31(11):1267-71.

12. Kessler RC, McLaughlin KA, Green JG, Gruber MJ, Sampson NA, Zaslavsky AM, Aguilar-Gaxiola S, Alhamzawi AO, Alonso J. Childhood adversities and adult psychopathology in the WHO world mental health surveys. $\mathrm{Br}$ J Psychiatry. 2010;197(5):378-85.

13. Hughes K, Lowey H, Quigg Z. Relationships between adverse childhood experiences and adult mental well-being: results from an English national household survey. BMC Public Health. 2016;16(1):222

14. Lee MA. Emotional abuse in childhood and suicidality: the mediating roles of re-victimization and depressive symptoms in adulthood. Child Abuse Negl. 2015;44:130-9.

15. Arseneault L, Walsh E, Trzesniewski K, Newcombe R, Caspi A, Moffitt TE. Bullying victimization uniquely contributes to adjustment problems in young children: a nationally representative cohort study. Pediatrics. 2006; 118(1):130-8.

16. Rønning JA, Sourander A, Kumpulainen K, Tamminen T, Niemelä S, Moilanen I, Helenius H, Piha J, Almqvist F. Cross-informant agreement about bullying and victimization among eight-year-olds: whose information best predicts psychiatric caseness 10-15 years later? Soc Psychiatry Psychiatr Epidemiol. 2009;44(1):15-22.

17. Van Geel M, Goemans A. A meta-analysis on the relation between peer victimization and adolescent non-suicidal self-injury. Psychiatry Res. 2015; 230(2):364-8.

18. Klonsky ED. Non-suicidal self-injury in United States adults: prevalence, sociodemographics, topography and functions. Psychol Med. 2011;41(9):1981-6.

19. Law BM, Shek DT. A 6-year longitudinal study of self-harm and suicidal behaviors among Chinese adolescents in Hong Kong. J Pediatr Adolesc Gynecol. 2016;29(Suppl 1):S38-48.

20. Liu X, Tein JY. Life events, psychopathology, and suicidal behavior in Chinese adolescents. J Affect Disord. 2005;86(2-3):195-203.

21. Perera B, Ostbye T, Ariyananda PL. Prevalence and correlates of physical and emotional abuse among late adolescents. Ceylon Med J. 2009;54(1):10-5.

22. Jaiswal SV, Faye AD, Gore SP, Shan HR, Kamath HR. Stressful life events, hopelessness, and suicidal intent in patients admitted with attempted suicide in a tertiary care general hospital. J Postgrad Med. 2016;62(2):102-4.

23. Cerutti R, Manca M, Presaghi F, Gratz KL. Prevalence and clinical correlates of deliberate self-harm among a community sample of Italian adolescents. J Adolesc. 2011;34(2):337-47.

24. Zhang WC, Jia CX, Zhang JY, Wang LL, Liu XC. Negative life events and attempted suicide in rural China. PLoS One. 2015;10(1):e0116634.

25. Bernstein DP, Stein JA, Newcomb MD, Walker E, Pogge D, Ahluvalia T, Stokes J, Handelsman L, Medrano M, Desmond D, et al. Development and validation of a brief screening version of the childhood trauma questionnaire. Child Abuse Negl. 2003;27(2):169-90.

26. Bernstein DP, Fink L. Childhood trauma questionnaire: a retrospective selfreport manual. San, Antonio: TX; 1998.

27. Solberg ME, Olweus D. Prevalence estimation of school bullying with the Olweus bully/victim questionnaire. Aggress Behav. 2003;29(3):239-68.

28. Wang J, lannotti RJ, Nansel TR. School bullying among adolescents in the United States: physical, verbal, relational, and cyber. J Adolesc Health. 2009; 45(4):368-75.

29. Smith PK, Cowie H, Olafsson RF, Liefooghe AP, Almeida A, Araki H, del Barrio C, Costabile A, Dekleva B, Houndoumadi A, et al. Definitions of bullying: a comparison of terms used, and age and gender differences, in a fourteencountry international comparison. Child Dev. 2002;73(4):1119-33.

30. Hu Y, Tao FB, Su PY, Qi XX, Xing C, Huang ZH. Compilation and reliability and validity assessment of multidimensional life events rating questionnaire for middle school student. Chin J Sch Health. 2010;31(2):146-9.

31. Liang BY, Huang Y, Ma LL. The development of the life stress rating scale for middle school students. Chin Ment Health J. 2002;16(5):313-6.
32. Chan KL. Victimization and poly-victimization among school-aged Chinese adolescents: prevalence and association with health. Prev Med. 2013;56(3-4):207-10.

33. Liu X, Sun Z. Parent-reported suicidal behavior and correlates among adolescents in China. J Affect Disord. 2008;105(1-3):73-80.

34. Lee WK. Psychological characteristics of self-harming behavior in Korean adolescents. Asian J Psychiatr. 2016;23:119-24.

35. Ge X, Hu TJ, Liu Y, Zhang WW, Yu TT, Wang GF, Yuan SS, Fang Y, Su PY. Study on the relationship between child abuse, parent-child separation in childhood and the aggressive behavior in adolescence among 1417 junior high school students. Chin J Epidemiol. 2013;34(1):5-9.

36. Zung WW. A self-rating depression scale. Arch Gen Psychiatry. 1965;12(1): 63-70.

37. Wang XD, Wang XL, Ma H. Rating scales for mental health (updated version). Beijing: Chinese Mental Health Journal Club; 1999. p. 194-6.

38. Liu X, Tein JY, Zhao Z, Sandler IN. Suicidality and correlates among rural adolescents of China. J Adolesc Health. 2005;37(6):443-51.

39. Ziaei R, Viitasra E, Soares J, Sadeghi-Bazarghani H, Dastgiri S, Zeinalzadeh $\mathrm{AH}$, Bahadori F, Mohammadi R. Suicidal ideation and its correlates among high school students in Iran: a cross-sectional study. BMC Psychiatry. 2017; 17(1):147.

40. Law BM, Shek DT. Self-harm and suicide attempts among young Chinese adolescents in Hong Kong: prevalence, correlates, and changes. J Pediatr Adolesc Gynecol. 2013;26(Suppl 3):S26-32.

41. Tang J, Ma Y, Guo Y, Ahmed NI, Yu Y, Wang J. Association of aggression and non-suicidal self injury: a school-based sample of adolescents. PLoS One. 2013;8(10):e78149.

42. Weierich MR. Posttraumatic stress symptoms mediate the relation between childhood sexual abuse and nonsuicidal self-injury. J Consult Clin Psychol. 2008;76(1):39-44.

43. Garisch JA. Vulnerabilities to deliberate self-harm among adolescents: the role of alexithymia and victimization. Br J Clin Psychol. 2010;49(2):151-62.

44. Yang DM, Han WM, Shao CX, Su XX. Surveillance for self-injury and suicide among middle school students in Beijing Tongzhou District during 20082012. Chin J Sch Health. 2013;34(11):1351-3.

45. Ahmadi A, Schwebel DC, Bazargan-Hejazi S, Taliee K, Karim H, Mohammadi R. Self-immolation and its adverse life-events risk factors: results from an Iranian population. J Inj Violence Res. 2015;7(1):13-8.

46. Barrocas AL, Giletta M, Hankin BL, Prinstein MJ, Abela JR. Nonsuicidal selfinjury in adolescence: longitudinal course, trajectories, and intrapersonal predictors. J Abnorm Child Psychol. 2015;43(2):369-80.

47. Zhang J, Song J. Adolescent self-harm and risk factors. Asia Pac Psychiatry. 2016:8(4):287-95.

48. Sunnqvist C, Westrin A. Suicide attempters: biological stressmarkers and adverse life events. Eur Arch Psychiatry Clin Neurosci. 2008;258(8):456-62.

49. de Araújo RM, Lara DR. More than words: the association of childhood emotion abuse and suicidal behavior. Eur Psychiatry. 2016;37:14-21.

50. Lin PY. Association between serotonin transporter gene promoter polymorphism and suicide: results of a meta-analysis. Biol Psychiatry. 2004; 55(10):1023-30

51. Mirkovic B, Laurent C, Podlipski MA, Frebourg T, Cohen D, Gerardin P. Genetic association studies of suicidal behavior: a review of the past 10 years, progress, limitations, and future directions. Front Psychiatry. 2016;7:158

\section{Submit your next manuscript to BioMed Central and we will help you at every step:}

- We accept pre-submission inquiries

- Our selector tool helps you to find the most relevant journal

- We provide round the clock customer support

- Convenient online submission

- Thorough peer review

- Inclusion in PubMed and all major indexing services

- Maximum visibility for your research

Submit your manuscript at www.biomedcentral.com/submit 